\title{
Teaching Professional Ethics in Mexican and Spanish Universities
}

\author{
A. Hirsch, C. Navia** \\ * National Autonomous University of Mexico \\ ** National Pedagogical University, Ajusco Campus - Mexico
}

\begin{abstract}
The main purpose of this presentation is to explore the proposals to teach professional ethics to university students, which were expressed by scholars from institutions in Mexico and Spain. The ideas and results we present, derive from current formative proposals and from the application of surveys and a scale questionnaire to professors from the National Autonomous University of Mexico and some Spanish universities, within different phases and times. Coincidences have been encountered towards the central idea that the scientific and technical contents should be addressed in a conjoint manner with those about professional ethics. We found consensus in certain contents, for instance, the principles of professional ethics and participative formative strategies that should be employed, taking into account the work context and real situations. Among the conclusions, it can be highlighted that in general the majority of the professors interviewed have considered the necessity to include a preparation in this domain, in an explicit, systematic and articulated way with the research processes for university students.
\end{abstract}

Keywords: Teaching Professional Ethics; Professors; Universities; Mexico; Spain

\section{Introduction}

This paper is part of the Research Project about Professional Ethics at the National Autonomous University of Mexico (UNAM). The main objectives are: to contribute in the enrichment of knowledge about professional ethics at the university, and ultimately, to propose a series of guidelines for their teaching.

The previous papers, articles and book chapters we published articulated theoretical issues with empirical data. They focused in gathering and generating knowledge about professional ethics, with the idea to fulfil the first objective of the research project. Unlike the previous effort, in this work, we are committed to answer the second porpoise, which is the definition of guidelines for teaching professional ethics for university students.

The research has been developed through many years, in two different countries: Mexico and Spain. We believe that one of the achievements of this paper is the comparative analysis from the results in the research in both countries.

We present the research that was undertaken with Mexican and Spanish professors about the contents and methodologies to promote the teaching of professional ethics for university students. At the beginning of the research project, we search for implemented proposals in some universities, especially in Spain, about this theme. The topic was later investigated at the graduate level, among different stages, with professors from UNAM and various Spanish universities.

We will present the following aspects: the background of the research project; the process for gathering information through three strategies: documental analysis, interviews and a questionnaire; the central elements of the theoretical framework; the methodological section that refers to the application of the two empirical instruments; the discussion of the principal comparative findings; conclusions and the bibliographical references. 


\section{The research project background}

At the beginning of the research project (2002) we constructed the first State of the Art about professional ethics, recuperating empirical studies that were made in Mexico (Hirsch, "et al.", 2003). Ten years later, we participated in the second State of the Art (Hirsch, 2013).

Simultaneously we searched for bibliographical and periodical materials with the finality to construct the theoretical framework and to be able to define their principal elements. Even thought we have more or less completed this construction, we have and open mind about it, because we found new materials and open new topics that were not previously considered.

The third activity refers to the empirical phase, with the construction of a questionnaire (with an open question about the principal features of "being a good professional" and an attitude scale with 55 items). This instrument was developed between UNAM and the University of Valencia, in 2003, for the graduate level. We first applied the questionnaire to a sample of students in Valencia and Murcia in Spain, in 2003 - 2004 and later on in Mexico, in UNAM, to a sample of students in $2004-2005$ and a sample of professors and researchers in 2006 - 2007.

We also developed an interview guide that was used with professors from some Spanish universities in 2004 and 2011 and in UNAM with the forty graduate program coordinators in 2009. All of this allowed us to achieve the first objective of the research that is the enrichment of knowledge in this specific applied ethic.

At the same time, we searched for proposals to teach professional ethics to university students. This paper emphasizes the second porpoise which is the definition of guidelines about teaching professional ethics. We recover some of the proposals we found and also the answers given by the research subjects to direct questions about this theme.

\section{Methods}

In this paper, the acknowledgement of the retrieved information is given through three data collection strategies: documental analysis, interviews and a questionnaire. The instruments were structured, taking into consideration the theoretical framework specifically built for the research project. We analyzed the work of many authors from several countries, and chose as fundamental: Tom Beauchamp and James Childress (2012) from the United States of America; Augusto Hortal (2002) from Spain and Martin Aluja and Andrea Birke (2004) from Mexico.

The theoretical framework is composed by the following elements: professional ethics principles and rules, professional characterization in general and professional ethics in particular, professional ethics as part of the applied ethics; differences between professional ethics and professional deontology; economic, technical and organizational influences in professional practice; fundamental values, especially responsibility, dilemmas and ethical conflicts, non-ethic behaviour, professional identity, science ethics and research ethics, professional ethics of professors and proposals for teaching ethics in the university. 


\section{Professional ethics principles}

During the long process of constructing the theoretical framework we realised that the central theme was about the principles of professional ethics. Even though mostly all the literature we consulted referred to that topic, we decided to focus in a very important book from Tom Beauchamp and James Childress (2012): Principles of Biomedical Ethics.

The four moral principles presented by them are: Respect for Autonomy, Nonmaleficence, Beneficence and Justice. In the preface of the seventh edition, they clearly expressed "that it is a mistake to assign priority to any basic principle over other basic principles" and that "the better strategy is to appreciate the contributions and the limits of various principles, virtues, and rights”.

These four principles are fundamental to biomedical ethics, but because they have proved to be significant as a reflection framework to take ethical decisions in the conflicts and dilemmas that professional encounter in their daily work, they have been recovered and interpreted by the other areas of knowledge.

Respect for autonomy means "self - rule that is free from both controlling interference by others and limitations that prevent meaningful choice, such as inadequate understanding. The autonomous individual acts freely in accordance with a self-chosen plan... In contrast, a person of diminished autonomy is in some material respect controlled by others or incapable of delivering or acting on the basis of his or her desires and plans... (p. 101-102).

"The principle of Nonmaleficence obligates us to abstain from causing harm to others"(p. 150). This principle supports several specific rules. Beauchamp and Childress (2012:154) prioritized: do no kill, do not cause pain or suffering, do no incapacitate, do not cause offense and do not deprive others the goods of life”.

The risk of harm in the biological and health sciences and in the scientific research in all areas of knowledge has been enormous in relation to the vulnerable people and communities: "the unjustified overutilization of members of these populations has long been a matter of deep moral concern” (p. 156).

In reference to the principle of Beneficence, the authors distinguish two related concepts: positive beneficence and utility. The first one "requires agents to provide benefits to others" and the second "requires that agents balance benefits, risks and costs to produce the best overall results” (p. 202).

The principle of Justice search to "determine how social burdens, benefits, opportunities, and positions ought to be distributed". They consider that our obligations are limited to fundamental needs for essential resources (p. 252).

The empiric work was performed in four phases within Mexican and Spanish universities. The documental strategy allowed us to obtain concrete proposals on how teaching professional ethics is performed among educational institutions.

\section{Interview program}

The interview strategy was used on two occasions in Spain. The first one, in 2003 2004 (Hirsch, 2004), comprised eleven professors: Pedro Ortega from Murcia University; Bernardo Martínez-Mut and José Felix Lozano from the Polytechnic University of Valencia; Gonzalo Jover from the Complutence University of Madrid; Juan Manuel Cobo, Augusto Hortal and Julio Martínez-Martínez from the Pontifical 
University of Comillas in Madrid; Miguel Angel Santos and María del Mar Lorenzo from the Santiago of Compostela University and Juan Escámez and Rafaela GarcíaLópez from the University of Valencia.

From the eleven academics that were interviewed, several criteria were prioritized, knowledge, experience and concrete formative proposals from three experts on the thematic field. These professors are Augusto Hortal (1995 and 2002) and Juan Manuel Cobo (2003 and 2004) from the Pontifical of Comillas University in Madrid and José Félix Lozano (2000 and 2003) from the Polytechnic University of Valencia. The principal questions that were sought to be answered were: Why it is important to teach professional ethics? How this formative need can be solved? What to teach on professional ethics?

The second interview was performed in 2011. The principal feature of the Spanish respondents in 2003 -2004 was that they all were active in philosophy and educational sciences. Those performed in 2011 included professors from other disciplines. Eleven of the fourteen interviews were made in the University of Valencia, with the following academics: Juan Escámez, Cruz Pérez, Bernardo Gargallo, Rafaela García-López, Victoria Vázquez, Inmaculada López, Manuel Dolz, Pilar Martínez-Arocas, Vicente Barberá, Rafael Pla and María Carmen Antolín. The other three were: José Felix Lozano from the Polytechnic University of Valencia and Roberto Sanz and Lucía Ballester from the Catholic University of Valencia San Vincent Martyr.

The interview guide was applied in 2009, to the forty coordinators of all the graduate programmes at UNAM. This university classifies its forty graduate programmes in four distinct areas of knowledge: Physics - Mathematical and Engineering Sciences (with seven graduate programmes: Mathematical Sciences and the Specialization of Applied Statistics, Engineering, Astrophysics, Computational Science and Engineering, Science and Engineering of Materials, Earth Sciences and Physical Sciences); Biological, Chemical and Health Sciences (with ten graduate programmes: Biomedical Sciences, Neurobiology, Nursery, Biochemical Sciences, Production and Animal Health, Medical - Dentistry and Health Sciences, Chemical Sciences, Psychology, Biological Sciences and Sea and Limnology Sciences); Social Sciences (with eight programmes: Social Work, Anthropology, Administration Sciences, Political and Social Sciences, Law, Economy, Latin-American Studies and Geography) and Humanity and Arts (with fifteen programmes: Industrial Design, Master in Teaching for the College Level, Architecture, Library Sciences and Informational Studies, Mesoamerican Studies, Philosophy, Philosophy of Science, History, Literature, Linguistics, Music, Pedagogy, Urbanity, Art History and Arts and Design).

Considering that the interview guide was applied in different moments and countries, the questions were adapted as the research was advancing in its course.

\section{A scale questionnaire about professional ethics}

A scale questionnaire was designed and applied to a sample consisting in 719 professors from UNAM in 2009. The questionnaire was structured as follows: four major open questions and an attitude scale about professional ethics integrated with 55 items (Hirsch, 2010). From this instrument we only included in this paper the open question: Do you consider that professional ethics should be taught to all university students? If your answer is affirmative: Which are the main contents and strategies to be implemented? 
The sample was of 384 men (53.40\%) and 335 women (46.59\%). The highest percentage was from professors in the age range of 46 to 50 years $(21.97 \%)$ and in the wider one from 46 to more than 60 years $(70.38 \%)$. The data about the age is coincident with the academic antiquity, because the highest percentage is the group of teachers and researchers with 30 years of service $(20.59 \%)$. The two following places in a descendant order are 21 to 25 years and 26 to 30 years working in UNAM. In these three we found more than half of the sample (50.91\%).

$70.51 \%$ had a PHD and $24.34 \%$ a Master. In the sample, we located $13.35 \%$ of subjects' teachers, $13.07 \%$ researchers and $11.40 \%$ professors with the highest category and level. The instrument was also answered by seven emeritus professors $(0.98 \%)$. The rest was situated in a dispersed manner in the other academic categories and levels of UNAM.

For the analysis of the information gathered, categories and subcategories were constructed in order to cluster the responses from the informants. These categories allowed us to establish comparisons.

\section{Results and Discussion}

\section{First moment: experts from Spanish universities}

In a first encounter, in 2004, experts from Spanish universities were interviewed about teaching professional ethics. One trend we found is that the professors considered that even though scientific-technical knowledge is central, ethical considerations are also important. This affirmation is relevant, since a predominant cognitive and ethical content was found on the professional formation of university students.

The experts (mainly philosophers and educational science professors) also considered that the systematic reflection on basic principles should be fostered among students, such as Beneficence, Non-Maleficence, Autonomy and Justice (Beauchamp \& Childress, 2012). They expressed the necessity to teach essential ethic values, mainly responsibility; the goods and services that each profession provides to society, the direct and indirect people benefited; their rights and obligations and the dilemmas and ethical conflicts that they could face in their professional practice.

A fact is highlighted, which consists in the consideration that the methodology employed at universities about professional ethics should be practical, participative, and group-oriented. Conversely, the experts thought on the possibility to include additional professional ethics-related subjects, as part of the curriculum in all university programmes. This consideration encompassed the support of the presentation of all topics with examples, to utilize problem-solving methods and professional case study techniques involving ethical dilemmas and analyzing the ethical codes of each profession or of each knowledge area, considering the interdisciplinary actual practice.

Second moment: graduate professors from the National Autonomous University of Mexico (UNAM)

A questionnaire which included an attitude scale about professional ethics was applied at UNAM between 2006 and 2007 to a sample of 719 professors representing the forty graduate programs. As we indicated before, one of the open questions asked was if they considered the need (or not) of a compulsory subject about professional ethics for all students, its contents and strategies. The majority of professors agreed on the necessity to implement that type of subjects. 
Even though it was clearly presented that the survey instrument was about professional ethics, some interviewed professors responded on aspects that were directly linked to general or civic ethics. It was surprising to find the fact, that professors had difficulties to differentiate these three theoretical ambits. From one side, general ethics has a considerable abstraction level and the civic ethics on the other hand, - which is an application field - refers fundamentally to the citizen's sphere. The professional domain is distinct from the other ethics, because it comprises its own theoretical framework, specific values and particular experiences that are associated on a high degree to the work space. This difficulty could be related to the fact that some values are common between professional and civic ethics (both ethics are applied), such as responsibility, honesty and respect. In this research these values were classified as binding values.

The matters that are directly linked to professional ethics that were highlighted by the respondents were: social competencies, legality, norms and principles; non-ethical behaviour and their consequences; identity; cognitive competencies; professional values; the orientation that professional ethics has to be able to take adequate decisions; ethics in the scientific and technological research and teacher's professional ethics.

In order to teach this thematic, some of the ideas are: it is important to generate transversal contents; "to teach with the example" and to recognize the contribution of a good professional practice in relation to society. It is significant that, as for the phase previously described, many of the responses emphasized the use of participatory methodologies, such as case study workshops, critical analysis of the professional practice, a good preparation for professors in this field of knowledge, and ultimately, to create communitarian participation activities.

\section{Third moment: coordinators of graduate programmes at UNAM}

In 2009, coordinators of the forty graduate programmes from UNAM were interviewed about the encouragement of professional ethics on students. The most quoted response was that this encouragement was mainly performed through professors and mentors. We believe that this fact is relevant, because it emphasizes the formative contribution of interaction among professors and students.

It was mentioned as well, that it is associated to the research processes and to the search of higher levels of intellectual capacity. Another area of responses dealed with guidelines, reflection about behaviour and ethical dilemmas, values such as responsibility in general, social responsibility and honesty, trans-disciplinary strategies, collaborative work, integral education and the acknowledgement of effort and hard work.

\section{Fourth moment: professors from universities in Valencia}

Fourteen professors from three universities in Valencia - Spain were interviewed in 2011 on how to teach students the importance and principal contents about professional ethics. Responses pointed to two main postures. One of these established the possibility to implement professional ethics-related subjects on the programme curriculum, with the idea that this determination contributes to the reflection of this knowledge field. Other professors expressed, that this problematic should be addressed in a transversal manner, given the fact that some study plans are over-charged, and that these types of subjects are regarded as "soft skills" or subjects that do not need formal examination processes.

In general, a combination of several strategies was proposed, such as the practical study cases, to work situations that contain ethical dilemmas and conflicts, re-take 
experiences, to invite professionals to explain the ethical problems that they have encountered, and finally, to foster student's awareness. We found certain coincidences among the professors on the strategies and on setting the students in a context in which they will be prepared to take ethical decisions.

\section{Conclusions}

Professional ethics is a relevant current matter. Within the diverse stages and countries (Mexico and Spain), where this research was performed, a great coincidence on the identification of severe problems in the domain of work were encountered. Such issues were linked to conflicts, ethical dilemmas and non-ethical behaviour.

From the phases that were described, it can be highlighted that in the view of the majority of the interviewed professors, professional ethics is a significant and necessary matter for the integral education of students, and that it can be taught through explicit and systematic strategies.

There was an agreement on the strategies that were applied by the university professors, such as study cases, approach of dilemmas and ethical conflicts. It was emphasized the need to count with exemplary situations based on real events, and the collaboration from active professionals that share their experiences with the students. Additionally, they expressed the need to generate problem solving methods; analysis of professional codes and service programmes.

It was stated - more associated to the scientific research processes - the relevance to generate ideas with respect to trans-disciplinarily and group-oriented work, the relationship within the production of knowledge and its possible application, the search of high levels of excellence and autonomy: both of students and professors and the development of skills associated to innovation. The professional identity was linked with the individual identity, considering the development along their personal life.

Also, certain relevance is highlighted about the professor - student link, and the participation of students on research processes. The idea related to the phrase "to teach with the example" was repeatedly expressed among the interviewed.

As it has been stated on the introduction, one of the main objectives related to the professional ethics research project in UNAM is to foster guidelines for teaching students this thematic field. What has been encountered - from the theoretical side and taking as a reference the empirical work that was conducted with professors from both Mexican and Spanish universities - was useful to outline such guidelines and formative strategies, in order to put them into practice.

\section{References}

Aluja, M. \& Birke, A. (2004). General panoramic about the ethical principles in scientific research and higher education. In M. Aluja and A. Birke (Eds.), The role of scientific ethical research and higher education, (pp. 87-143). Mexico, Economical Culture Publisher and Mexican Academy of Science.

Beauchamp, T. \& Childress, J. (2012). Principles of Biomedical Ethics. $7^{\circ}$ edition, New York, Oxford University Press. 
Cobo, J.M. (2003). Pedagogy Curriculum: Fourth Subject (2003-2004). Madrid, Spain, Pontifical University of Comillas in Madrid.

Cobo, J.M. (2004). University and Professional Ethics. Educational Theory Interuniversity Journal, 15, 258-276.

Hirsch, A., "et al." (2003). University and Professional Values Researches. In M. Bertely, (ed.), Education, Social Rights and Equity. Educational Research in México 1992-2002 (pp. 1007-1032). Mexico, Mexican Council of Educational Research, Ministry of Public Education and UNAM.

Hirsch, A. (2004). Utopia and University: Teaching Professional Ethics. Reencounter: Analysis of University Problems, 41, 32-37.

Hirsch, A. (2010). Considerations of the Graduate Professors of UNAM about the Necessity to Offer a Professional Ethics Subject for all the Alumni. In A. Hirsch (Ed.), Ethics, Values and Socio-Cultural Diversity (pp. 5-28). Mexico, National Council of Science and Technology, National Autonomous University of Mexico and Díaz de Santos Editions.

Hirsch, A. \& Pérez-Castro, J. (2013). State of the Art about Professional Values and Professional Ethics. In A. Hirsch \& T. Yurén. (Eds.), The Research in Mexico in the Field of Education and Values 2002 - 2011 (pp. 79-149). Mexico, National Association of Universities and Institutions of Higher Education and Mexican Council of Educational Research.

Hortal, A. (1995). Professional Ethics in the University Context. In Deusto University (Ed.), Ethics Classroom. Ethics in the University. Basic Orientations (pp. 57-71). Spain, Deusto University.

Hortal, A. (2002). General Ethics of Professions. Spain, Desclée de Brouwer.

Lozano, J.F. (2000). Engineering Ethics Pedagogy. Education and Pedagogy Journal, 28, 59-67.

Lozano, J.F. (2003). Ethical Responsibility in Engineering: A Foundation and Proposition of a Pedagogic Methodology. Proceedings of the International Conference on Engineering Education, Valencia, Spain, 21-25. 